\title{
Sex differences in mandibular repositioning device therapy effectiveness in patients with obstructive sleep apnea syndrome
}

\begin{abstract}
Marie-Françoise Vecchierini ${ }^{1,2} \cdot$ Valérie Attali ${ }^{3,4}$. Jean-Marc Collet ${ }^{5}$. Marie-Pia d'Ortho ${ }^{6,7}$. Frederic Goutorbe ${ }^{8}$. Jean-Baptiste Kerbrat ${ }^{5,9} \cdot$ Damien Leger $^{1,2}$. Florent Lavergne ${ }^{10}$. Christelle Monaca ${ }^{11}$. Pierre-Jean Monteyrol ${ }^{12}$. Laurent Morin $^{10} \cdot$ Eric Mullens $^{13} \cdot$ Bernard Pigearias $^{14} \cdot$ Francis Martin $^{3} \cdot$ Hauria Khemliche $^{15} \cdot$ Lionel Lerousseau $^{16}$. Jean-Claude Meurice ${ }^{17}$. on behalf of the ORCADES investigators - Darius Abedipour - Aurélie Allard-Redon . Alexandre Aranda • Valérie Attali • Frédérique Bavozet • Martine Becu • Wally Beruben • Jerome Bessard • Isabelle Bonafe - Mohammed Boukhana • Bruno Chabrol • Gérard Chatte • Chauvel Lebret • Jean-Marc Collet • Olivier Coste • Nathalie Dumont • Sophie Durand-Amat • Marie-Pia D'ortho • Jean Marc Elbaum • Olivier Gallet De Santerre • Frédéric Goutorbes • Thierry Grandjean • Wilma Guyot • Doniphan Hammer • Carmen Havasi - Pascal Huet • Jean Baptiste Kerbrat • Hauria Khemliche - Christian Koltes • Damien Leger • Laurent Lacassagne - Xavier Laur • Lionel Lerousseau • Olivier Liard • Christophe Loisel • Matthieu Longuet • Anne Mallart • Francis Martin • Frédéric Merle Beral • Jean Claude Meurice • Zoubida Mokhtari • Christelle Monaca • Pierre Jean Monteyrol - Jean-François Muir • Eric Mullens • Dominique Muller • Charles Paoli • François Xavier Petit • Bernard Pigearias - Marc Pradines • Arnauld Prigent • Gil Putterman • Marc Rey • Mickael Samama • Renaud Tamisier • Michel Tiberge • Cyrille Tison • Fabienne Tordjman • Bernard Triolet • Christian Vacher • Marie-Françoise Vecchierini • Alain Verain
\end{abstract}

Received: 11 August 2018 / Revised: 2 November 2018 / Accepted: 27 November 2018 / Published online: 22 December 2018

(C) The Author(s) 2018

\begin{abstract}
Purpose Mandibular repositioning devices (MRDs) are an effective treatment option for obstructive sleep apnea syndrome (OSAS), particularly in patients who refuse or cannot tolerate continuous positive airway pressure (CPAP). However, sex differences in the response to therapy and predictors of response are not clearly defined. This analysis of data from the longterm prospective ORCADES trial compared MRD efficacy in men and women with OSAS.

Methods The ORCADES study included patients with newly diagnosed mild-to-moderate or severe OSAS who refused or were noncompliant with CPAP. MRD therapy was titrated over 3-6 months. The primary endpoint was treatment success $(\geq 50 \%$ decrease in apnea-hypopnea index (AHI)). Complete response was defined using a range of AHI cut-off values $(<5 / \mathrm{h},<10 / \mathrm{h},<15 / \mathrm{h})$.
\end{abstract}

Florent Lavergne

florent.lavergne@ resmed.fr

1 AP-HP, Centre du Sommeil et de la Vigilance, Hôpital Hôtel Dieu, Paris, France

2 Sorbonne Paris Cité, Université Paris Descartes, Paris, France

3 Service des Pathologies du Sommeil (Département "R3S"), AP-HP groupe hospitalier Pitié-Salpêtrière Charles Foix, Paris, France

4 INSERM, UMRS1158 Neurophysiologie Respiratoire Expérimentale et Clinique, Sorbonne Université, Paris, France

5 AP-HP, Stomatologie et Chirurgie Maxillo-Faciale, Groupe Hospitalier Pitié-Salpêtrière Charles Foix, Paris, France

6 AP-HP, DHU FIRE, Physiologie et Explorations Fonctionnelles, Hôpital Bichat-Claude Bernard, Paris, France

7 UFR de Médecine, Université Denis Diderot Paris 7, Paris, France
Centre Médecine du Sommeil, Centre Hospitalier de Béziers, Béziers, France

9 Stomatologie et Chirurgie Maxillo-Faciale, Hôpital Charles Nicolle, Rouen, France

10 ResMed Science Center, 292, Allée Jacques Monod, 69791 Saint-Priest CEDEX, France

11 Neurophysiologie Clinique, Hôpital Roger Salengro, Lille, France

12 Polyclinique du Tondu, Oto-Rhino-Laryngologie, Bordeaux, France

13 Fondation Bon Sauveur, Laboratoire du Sommeil, Albi, France

14 Laboratoire du Sommeil, Nice, France

15 Groupe Hospitalier Public Sud de l'Oise, Senlis, France

16 Service de Pneumologie, Centre Hospitalier Antibes, Antibes, France

17 Pneumologie, Centre Hospitalier Universitaire, Poitiers, France 
Results Overall treatment success rates were $89 \%$ in women and $76 \%$ in men $(p=0.019)$; corresponding rates in those with severe OSAS (AHI $>30 / \mathrm{h})$ were $100 \%$ and $68 \%(p=0.0015)$. In women vs. men, overall complete response rates at AHI cut-off values of $<5 / \mathrm{h},<10 / \mathrm{h}$, and $<15 / \mathrm{h}$ were 49 vs. $34 \%(p=0.0052), 78$ vs. $62 \%(p=0.016)$, and 92 vs. $76 \%(p=0.0032)$. On multivariate analysis, significant predictors of MRD treatment success were overbite and baseline apnea index in men, and neck circumference and no previous CPAP therapy in women. There were sex differences in the occurrence of side effects. Temporomandibular joint pain was the most common reason for stopping MRD therapy.

Conclusions MRD therapy was effective in women with OSA of any severity, with significantly higher response rates compared with men especially in severe OSAS.

Trial registration www.clinicaltrials.gov (NCT01326143).

Keywords Obstructive sleep apnea $\cdot$ Mandibular repositioning device $\cdot$ Sex differences $\cdot$ Apnea-hypopnea index

\section{Introduction}

Obstructive sleep apnea syndrome (OSAS) is characterized by repetitive complete or partial occlusions of the upper airway with persistent inspiratory efforts during sleep, followed by oxyhemoglobin desaturations and terminated by arousals. OSAS is a public health burden because of its medical and socioeconomic consequences, including a higher likelihood of vehicle crashes and occupational accidents, increased risk of cardiovascular diseases, neurocognitive dysfunction, and impaired quality of life [1].

The gold standard treatment for OSAS is continuous positive airway pressure (CPAP), which has been shown to reduce sleepiness [2] and road accidents [3], and might decrease cardiovascular risk and mortality [4]. However, compliance with CPAP is an issue in up to half of all users [5], potentially limiting its effectiveness [6]. Mandibular repositioning devices (MRDs) enlarge the upper airway during sleep by holding the mandible in a forward position and are an effective alternative to CPAP, particularly in mild-to-moderate OSA or in patients not adherent to or refusing CPAP [7]. Reductions in the apnea-hypopnea index (AHI) during MRD therapy are usually smaller than those during CPAP, but patient acceptability and compliance may be better, with similar quality of life and symptom benefits [8].

The reported prevalence of OSAS is generally lower in women vs. men, and there are a number of sex-related differences in disease manifestation and presentation [1]. Mechanisms underlying sex differences in OSAS prevalence are not fully understood $[9,10]$, and there is a relative lack of data on sex differences in the response to OSA therapies, particularly MRDs.

The prospective ORthèse d'avanCée mAndibulaire type O.R.M dans le traitement en DEuxième intention du SAHOS sévère (ORCADES) cohort study is investigating the long-term efficacy and tolerability of a computer-aided design (CAD)/ computer-aided manufacturing (CAM) MRD in OSA patients non-compliant with or intolerant of CPAP. Interim short-term results showed that MRD treatment was effective across all severities of OSAS, and univariate logistic regression analysis of factors predicting efficacy indicated better MRD efficacy in women than in men (hazard ratio $2.12,95 \%$ confidence interval $1.21-3.73 ; p=0.0078$ ), although this did not persist in multivariate analysis [11]. This post hoc analysis of the ORCADES study compared CAD/CAM MRD efficacy in men and women after 3-6 months follow-up.

\section{Methods}

\section{Study design and oversight}

The prospective, observational ORCADES study (NCT01326143) was conducted at 28 centers in France. The study design and details of MRD devices have been described in detail previously [11]. The Steering Committee (SC) defined the study design and was responsible for the clinical and scientific conduct of the study and publication of the results. C.R.O. Clinact (France) performed the data collection, quality control, management, and analysis. The SC had full access to all data and takes responsibility for the integrity and accuracy of the analysis.

\section{Patients}

Eligible patients had newly diagnosed mild-to-moderate (AHI 5-30/h) or severe $($ AHI $>30 / \mathrm{h})$ OSAS, excessive daytime sleepiness (Epworth Sleepiness Scale (ESS) score $>10$ ), and refusal of or non-compliance with CPAP. Exclusion criteria included previous MRD treatment, contraindications to MRD therapy, central apnea index $>5 / \mathrm{h}$, severe sleep comorbidities other than OSAS, and coexisting psychiatric disease.

\section{MRD titration and follow-up}

Patients were fitted with a CAD/CAM MRD (Narval CC ${ }^{\text {TM}}$; ResMed). Mandibular advancement was gradually adjusted at the discretion of the dental sleep specialist (over a 15-mm range) until the best benefit-risk ratio between symptom resolution and tolerability was achieved. At titration visits, 
patients reported the degree of improvement (none, some, important) in three symptoms (snoring, fatigue, and sleepiness) and also rated tolerability (based on articular, dental, and periodontal pain) on a non-graduated, $10-\mathrm{cm}$ visual analogue scale.

\section{Assessments and endpoints}

The primary endpoint was treatment success (proportion of patients with $\mathrm{a} \geq 50 \%$ decrease in AHI from baseline to follow-up). Complete response was defined using a range of AHI cut-off values $(<5 / \mathrm{h},<10 / \mathrm{h},<15 / \mathrm{h})$.

At baseline and follow-up visits, self-reported clinical symptoms were assessed, sleep quality, subjective sleepiness was scored using the ESS, quality of life using the Quebec Sleep Questionnaire (QSQ) and fatigue using the Pichot scale [11].

Sleep and/or nocturnal respiratory parameters were recorded at baseline and after 3 months with the same polygraphy (PG) or polysomnography (PSG) device used to diagnose OSA. If AHI decreased by $<50 \%$ and/or symptoms persisted, PSG/PG was performed again at 6 months after additional mandibular advancements. PSG/PG recordings were manually scored using American Academy of Sleep Medicine guidelines [12]. Positional OSA was defined when the supine AHI was at least twice that in other positions and AHI was > 10/h [13].

Self-reported MRD compliance (hours/night; nights/week) was reported at each follow-up visit, and comprehensive data on MRD-related side effects were collected. Side effect severity and impact on MRD treatment was determined by sleep and dental sleep physicians.

\section{Statistical analysis}

Quantitative changes from baseline to follow-up were presented as mean \pm standard deviation and compared using unpaired or paired Student's $t$ test or nonparametric test according to normality of distribution and group comparison. Qualitative changes were described using frequency distribution and compared using Fisher Exact or chi-square test. Comparisons between men and women were assessed using Student's $t$ test, ANOVA, or Wilcoxon-Mann-Whitney test. Three logistic models were created and backward stepwise regression analysis was used to determine independent factors associated with therapy success and complete response, model 1: all patients; model 2: men; and model 3: women. For all models, variables with a $p$ value $<0.10$ in the univariate analysis were entered in the stepwise logistic regressions, and variables with a $p$ value $<0.05$ were retained in the final models. For model 1 , univariate analysis on the interaction between gender and potential predictive factors was also performed. Statistical analyses were performed using SAS version 9 .

\section{Results}

\section{Study population}

A total of 515 eligible OSA patients (144 women, 371 men) were screened between May 2011 and September 2013; 154 with contraindications to MRD therapy or treatment with another MRD or who declined to participate were excluded. Therefore, 312 eligible patients ( 77 women, 235 men) were enrolled in our cohort study. Of these, 52 patients withdrew from the study before evaluation of the endpoint criteria, leaving 260 available for follow-up analysis (Fig. 1). There were significantly fewer women than men in the study population and there were a number of statistically significant betweengroup differences (Table 1). Women were older; had a lower body mass index (BMI), neck and waist circumference, and diastolic blood pressure; were more likely to have retrognathia, hypothyroidism, and positional OSA; and had a lower apnea index (AI) and non-supine AHI vs. men (Table 1). Women and men reported similar MRD use (6.7 and $6.6 \mathrm{~h} /$ night on 6.8 and 6.5 nights/week, respectively). Device use every night was reported by $85 \%$ of women and men, and device use $\geq 4 \mathrm{~h} /$ night on $\geq 4$ days/week by $100 \%$ of women and $94 \%$ of men. Women and men required a similar number of titration visits to optimize MRD efficacy (1.8 \pm 1.2), with similar final mean mandibular advancement ( 6.8 \pm 2.2 vs. $7.4 \pm 2.1 \mathrm{~mm} ; p=0.07)$ and percentage of maximal mandibular advancement (median $(\mathrm{Q} 1, \mathrm{Q} 3)$ 76.4\% (66.7, $100)$ vs. $83.3 \%(66.7,100) ; p=0.26)$.

\section{Primary endpoint: MRD efficacy}

Overall treatment success and complete response rates were significantly higher in women than in men (Fig. 2), primarily due to significant sex differences in the subgroup with severe OSA (success rate $100 \%$ in women vs. $67.7 \%$ in men, $p=$ 0.0015 ; complete response at $\mathrm{AHI}<5 / \mathrm{h},<10 / \mathrm{h}$, and $<15 / \mathrm{h}$ in 49 vs. $34.0 \%(p=0.0052), 78$ vs. $62 \%(p=0.016)$, and 92 vs. $76 \%(p=0.0032)$, respectively).

\section{Secondary endpoints: sleep and respiratory parameters}

There was a significant reduction in mean AHI, irrespective of sex (Table 2), again due to a significantly greater reduction in the severe OSA subgroup (Table 3). Mean AI, hypopnea in$\operatorname{dex}(\mathrm{HI})$, supine and non-supine AHI, nadir oxygen saturation $\left(\mathrm{SpO}_{2}\right)$, and time with $\mathrm{SpO}_{2}<90 \%$ decreased significantly from baseline to follow-up in men and women (Table 2), with the greatest decrease in HI seen in women with severe OSA (Table 3).

The ESS score decreased significantly during MRD therapy (from $10.6 \pm 5.3$ to $7.5 \pm 4.4$ in women and $11.4 \pm 4.7$ to 
Fig. 1 ORCADES study flow chart. $C A D / C A M$ computer-aided design/computer-aided manufacturing, $F U$ follow-up, $m$ men, MRD mandibular repositioning device, $w$ women

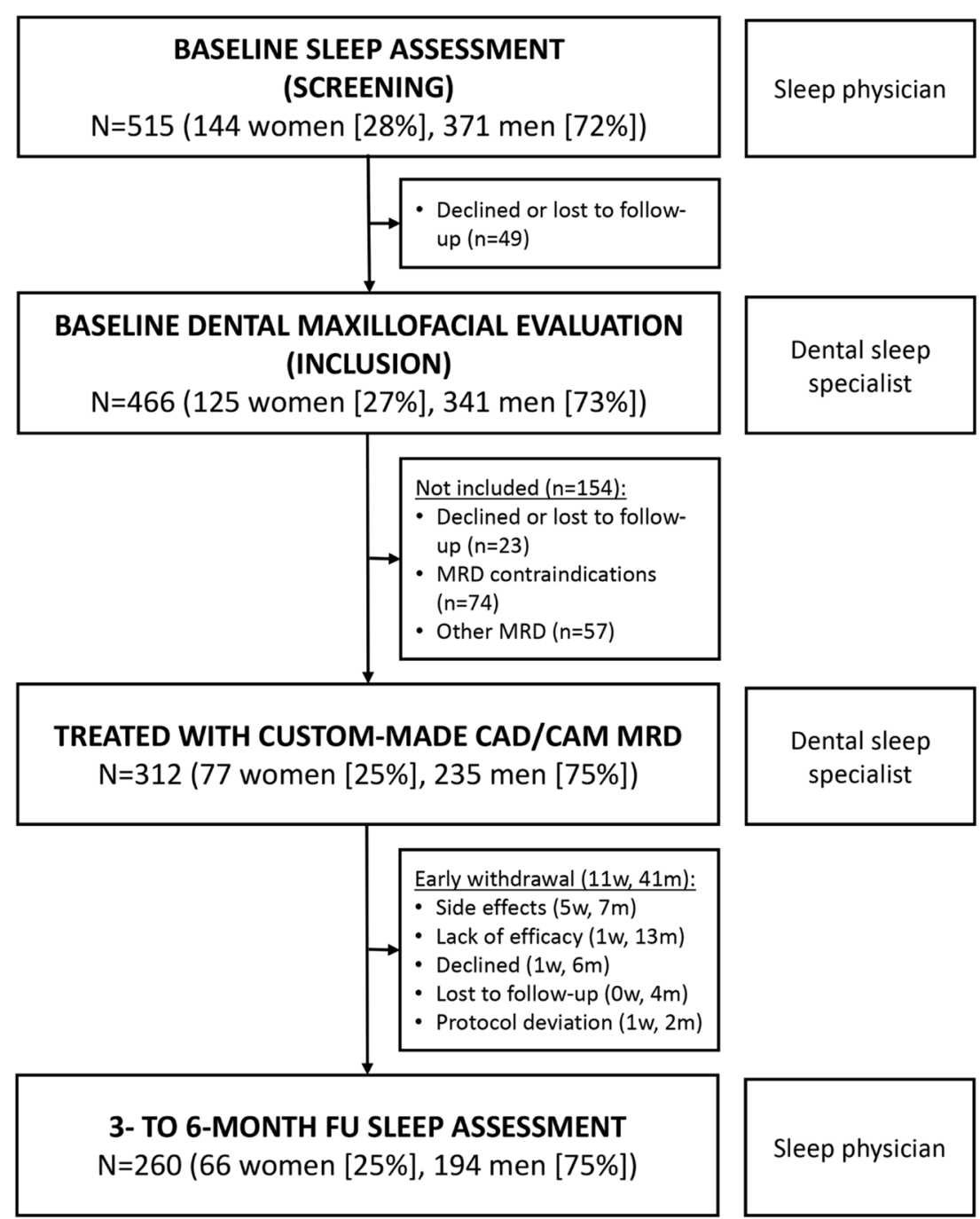

$7.9 \pm 4.3$ in men; $p<0.0001)$ with no sex differences. Excessive daytime sleepiness improved in $62 \%$ of men and women. Most clinical symptoms improved significantly in men and women after 3-6 months of MRD treatment; snoring disappeared in $53 \%$ of women and $48 \%$ of men. Self-reported symptoms, including sleep quality, awakening, nocturia, libido disorders, and mouth breathing, improved similarly in women and men. However, reduction of morning headache was more pronounced in women vs. men $(p=0.05)$. Mean total and domain scores on the QSQ significantly improved from baseline under MRD treatment $(+24 \%, p<0.0001)$, and were similar in men and women. The Pichot fatigue scale score also improved significantly and similarly in men and women $(-35 \%, p<0.0001)$.

Among the 149 patients who underwent PSG, there were no significant changes in total sleep time, sleep latency, N1+ N2 sleep, slow wave sleep, rapid eye movement sleep duration, and wake duration during sleep from baseline to followup, and no differences between women and men. Arousals decreased to a similar extent in men and women $(p<0.0001$ vs. baseline). Women slept less in the supine position during MRD therapy compared with baseline (Table 2); this was more marked in severe OSA (Table 3).

\section{Other parameters}

Body weight, BMI, blood pressure, and neck/waist circumference did not change significantly during MRD use, apart from a significant increase in waist circumference in men $(1.34 \pm$ $5.63 \mathrm{~cm}, p=0.0003$ vs. baseline).

\section{Factors predictive of MRD efficacy}

Model 1 (whole population) identified two significant independent predictors of MRD treatment success: initial AI and overbite, with no interactions by gender. A 10/h decrease in AI and a $1-\mathrm{mm}$ increase in overbite were associated with a 41 and $43 \%$ increase in the number of MRD responders, respectively. No significant predictors of complete response in the overall patient population were identified. For models 2 (men) and 3 
Table 1 Baseline characteristics by patient sex

\begin{tabular}{|c|c|c|c|}
\hline$N=312$ & Women & Men & $p$ value \\
\hline Number $(\%)$ & $77(24.7)$ & $235(75.3)$ & $<0.0001$ \\
\hline Age, years & $56.8 \pm 10.2$ & $52.1 \pm 11.2$ & 0.0013 \\
\hline Body mass index, $\mathrm{kg} / \mathrm{m}^{2}$ & $26.7 \pm 5.4$ & $27.2 \pm 3.5$ & 0.032 \\
\hline Obese, $N(\%)$ & $17(22.1)$ & $44(18.7)$ & NS \\
\hline Waist circumference, $\mathrm{cm}$ & $90.5 \pm 13.4$ & $98.9 \pm 11.2$ & $<0.0001$ \\
\hline Neck circumference, $\mathrm{cm}$ & $35.6 \pm 3.1$ & $41.0 \pm 3.1$ & $<0.0001$ \\
\hline Retrognathia, $N(\%)$ & $33(42.9)$ & $47(20)$ & 0.0006 \\
\hline Maximum mandibular advancement, $\mathrm{mm}$ & $8.7 \pm 2.5$ & $8.9 \pm 2.4$ & NS \\
\hline No previous CPAP therapy, $N(\%)$ & $45(58.4)$ & $107(45.7)$ & NS \\
\hline Systolic blood pressure, $\mathrm{mmHg}$ & $124.7 \pm 13.1$ & $127.6 \pm 11.2$ & NS \\
\hline Diastolic blood pressure, $\mathrm{mmHg}$ & $74.6 \pm 10.2$ & $78.9 \pm 9.7$ & 0.0032 \\
\hline \multicolumn{4}{|l|}{ Comorbidities, $N(\%)$} \\
\hline Arterial hypertension & $25(32.5)$ & $69(29.4)$ & NS \\
\hline Diabetes & $5(6.5)$ & $16(6.8)$ & NS \\
\hline Hypothyroidism & $11(14.3)$ & $4(1.7)$ & $<0.0001$ \\
\hline Stroke & $3(3.9)$ & $4(1.7)$ & NS \\
\hline Restless leg syndrome & $0(0)$ & $4(1.7)$ & NS \\
\hline \multicolumn{4}{|l|}{ Respiratory parameters } \\
\hline Mean AHI, /h & $26.5 \pm 13.7$ & $30.1 \pm 15.1$ & NS \\
\hline Mild OSA (AHI 5-15/h), N(\%) & $14(18.2)$ & 35 (14.9) & NS \\
\hline Moderate OSA (AHI 15-30/h), $N(\%)$ & $37(48.1)$ & $94(40.0)$ & NS \\
\hline Severe OSA (AHI > 30/h), $N(\%)$ & $26(33.8)$ & $106(45.1)$ & 0.08 \\
\hline Supine AHI, $/ \mathrm{h}$ & $32.2 \pm 17.9$ & $38.5 \pm 23.2$ & NS \\
\hline Non-supine AHI, /h & $13.1 \pm 15.3$ & $19.6 \pm 17.9$ & 0.0038 \\
\hline Positional OSA, $N(\%)$ & $45(58)$ & $82(35)$ & 0.0026 \\
\hline $\mathrm{AI}, / \mathrm{h}$ & $9.2 \pm 9.0$ & $13.8 \pm 13.0$ & 0.0044 \\
\hline $\mathrm{HI}, / \mathrm{h}$ & $17.2 \pm 10.1$ & $16.4 \pm 9.7$ & NS \\
\hline $\mathrm{cAI}, / \mathrm{h}$ & $0.3 \pm 0.8$ & $0.5 \pm 1.0$ & NS \\
\hline $\mathrm{SpO}_{2}, \%$ & $93.8 \pm 1.9$ & $93.7 \pm 1.9$ & NS \\
\hline Minimum $\mathrm{SpO}_{2}, \%$ & $83.0 \pm 6.8$ & $81.3 \pm 8.0$ & NS \\
\hline Time with $\mathrm{SpO}_{2}<90 \%$, min & $21.0 \pm 32.1$ & $26.5 \pm 55.7$ & NS \\
\hline ODI, /h & $21.8 \pm 19.3$ & $21.7 \pm 18.1$ & NS \\
\hline Snoring, $/ \mathrm{h}$ & $108 \pm 146$ & $143 \pm 276$ & NS \\
\hline Snoring duration, \% TRT & $27 \%$ & $29 \%$ & NS \\
\hline
\end{tabular}

$A H I$ apnea-hypopnea index, $A I$ apnea index, $c A I$ central apnea index, $C P A P$ continuous positive airway pressure, $H I$ hypopnea index, NREM non-rapid eye movement, $N S$ not significant, ODI oxygen desaturation index, OSA obstructive sleep apnea, $R E M$ rapid eye movement, $\mathrm{SpO} 2$ oxygen saturation

Values are mean \pm standard deviation, or number of patients (\%) (women), univariate analysis identified a number of significant predictive factors (Table 4). Significant independent predictors of MRD treatment success are summarized in Table 5. In men, a 10/h decrease in $\mathrm{AI}$ and a 1-mm increase in overbite were associated with a 50 and $48 \%$ increase in the number of MRD responders, respectively. In women, treatment success probability was increased by $27 \%$ by a $1-\mathrm{mm}$ increase in mandibular advancement. The similarity of independent predictors of treatment success overall and in men is probably due to the fact that men made up $75 \%$ of the total study population. For complete response, significant independent predictors included AHI in men, and neck circumference and no previous CPAP therapy in women (Table 5).

\section{Tolerability}

At least one side effect was reported by $55 \%$ of women and $49 \%$ of men, with some significant sex differences (Table 6); $12 \%$ of women and $7 \%$ of men discontinued MRD therapy for side effects $(p=0.017)$. Mouth or temporomandibular joint 


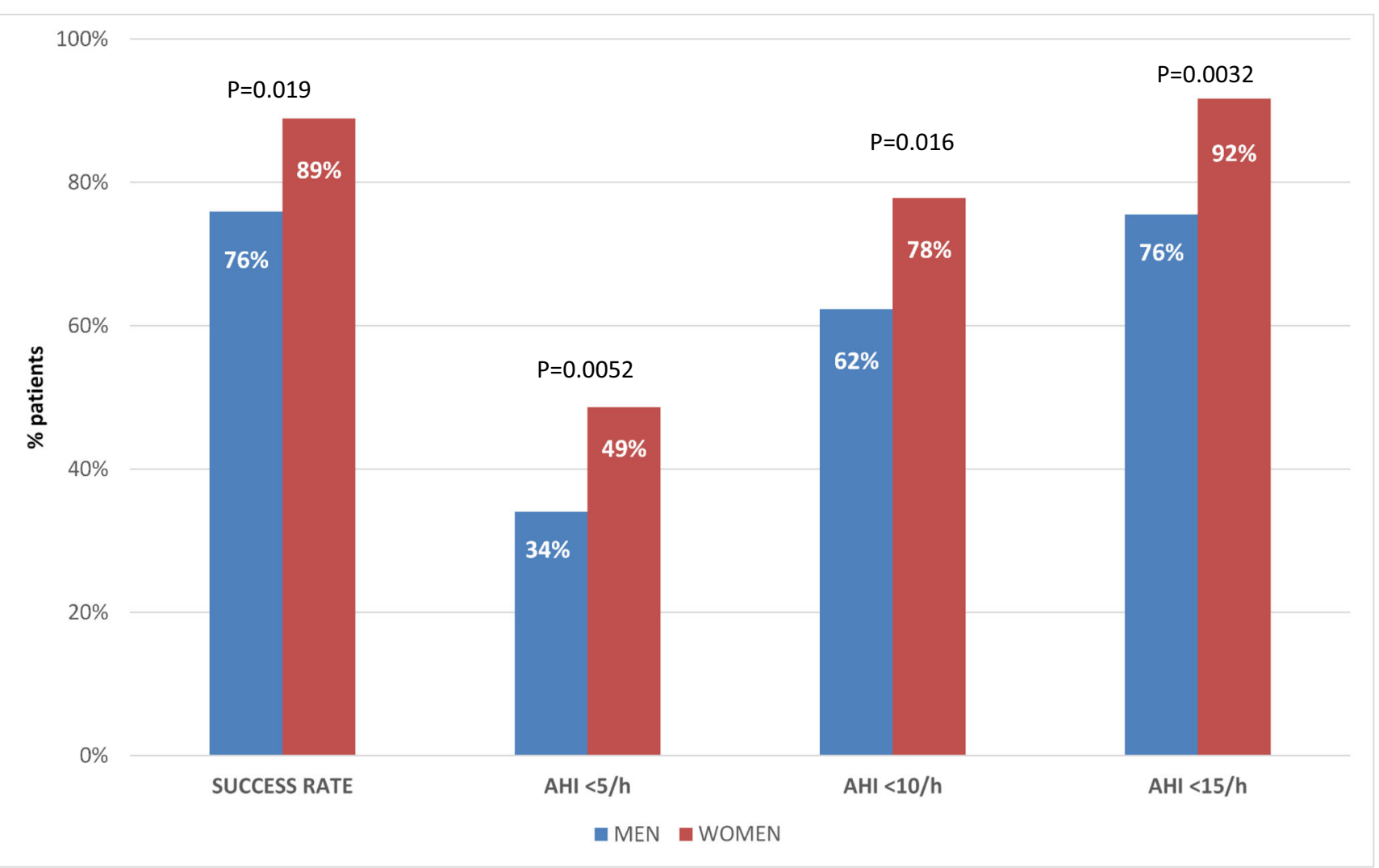

Fig. 2 Mandibular repositioning device efficacy in men and women at 3- to 6-month follow-up. AHI apnea-hypopnea index, Success rate percentage of patients with $\mathrm{a} \geq 50 \%$ decrease in AHI from baseline to follow-up

pain was responsible for $60 \%$ of treatment discontinuations (no difference between men and women).

\section{Discussion}

To the best of our knowledge, few studies have compared MRD treatment efficacy in women and men. All patients showed good compliance with therapy, but the treatment success rate was higher in women than in men, particularly in severe OSA. Complete response was also more common in women vs. men, across a range of AHI thresholds.

Previous data on sex differences in MRD effectiveness have reported conflicting results. One prospective observational study suggested that MRD effectiveness was greater in women vs. men [14], while data from a large retrospective cohort of OSA patients treated with an MRD did not find any link between sex and MRD treatment outcome [15]. Better MRD efficacy in women in our OSA cohort could be related to anthropometric and OSA characteristics. At baseline, BMI, waist, and neck circumferences were significantly lower in women, and during MRD use there was a tendency for reduced BMI only in women and increased waist circumference only in men. Obesity is known to be different between genders, with more central obesity in men. In a sleep clinic sample of women with OSA, fat in the neck region had a direct influence on airway patency, explaining 33\% of the between-sex variance in AHI [16]. In addition, higher BMI has been associated with lower MRD efficacy in some studies [17], particularly in men [14], and neck circumference may also predict MRD effectiveness [18]. This was confirmed in our study, where multiple regression analysis identified smaller neck circumference at baseline as a statistically significant independent predictor of MRD success in women. Men have a longer, softer oropharynx and a larger, fatter, more posterior tongue, increasing the probability of upper airway collapse $[19,20]$. The upper airway in men was found to be more collapsible than that in equally overweight/obese women [10]. These factors, not specifically investigated in our analysis, support a role for anthropomorphic and physiological factors in sex differences in the response to MRD treatment of OSA.

Several studies have reported a lower success rate with MRD therapy in patients with severe OSA [17], but others have found similar response rates across all OSA severities $[11,21]$. In our clinical sample, baseline OSA severity was similar in men and women and the proportion of patients with severe OSA was similar in the two groups, but treatment response in the severe OSA group was significantly better in women vs. men. Baseline AHI and HI were similar in men and women in our study, but AI was significantly lower in 
Table 2 Changes in respiratory parameters during MRD therapy by patient sex

\begin{tabular}{|c|c|c|c|c|c|}
\hline & \multirow[t]{2}{*}{ Baseline } & \multirow[t]{2}{*}{ Follow-up } & \multirow[t]{2}{*}{ Difference } & \multicolumn{2}{|l|}{$p$ value } \\
\hline & & & & vs. Baseline & Men vs. women \\
\hline \multicolumn{6}{|l|}{ AHI, /h } \\
\hline Women & $26.5 \pm 13.7$ & $6.5 \pm 5.4$ & $-19.3 \pm 11.7$ & $<0.0001$ & \multirow[t]{2}{*}{ NS } \\
\hline Men & $30.1 \pm 15.1$ & $11.6 \pm 13.2$ & $-18.7 \pm 12.6$ & $<0.0001$ & \\
\hline \multicolumn{6}{|l|}{$\mathrm{AI}, / \mathrm{h}$} \\
\hline Women & $9.2 \pm 9.0$ & $1.4 \pm 2.3$ & $-7.5 \pm 8.4$ & $<0.0001$ & \multirow[t]{2}{*}{0.084} \\
\hline Men & $13.8 \pm 13.0$ & $4.5 \pm 9.2$ & $-9.7 \pm 10.7$ & $<0.0001$ & \\
\hline \multicolumn{6}{|l|}{$\mathrm{HI}, / \mathrm{h}$} \\
\hline Women & $17.2 \pm 10.1$ & $5.1 \pm 4.4$ & $-11.4 \pm 8.7$ & $<0.0001$ & \multirow[t]{2}{*}{ NS } \\
\hline Men & $16.4 \pm 9.74$ & $7.2 \pm 7.73$ & $-9.0 \pm 10.4$ & $<0.0001$ & \\
\hline \multicolumn{6}{|c|}{ Supine AHI, $/ \mathrm{h}$} \\
\hline Women & $32.2 \pm 17.9$ & $7.6 \pm 6.8$ & $-22.7 \pm 15.7$ & $<0.0001$ & \multirow[t]{2}{*}{ NS } \\
\hline Men & $38.5 \pm 23.2$ & $13.8 \pm 17.81$ & $-24.3 \pm 23.0$ & $<0.0001$ & \\
\hline \multicolumn{6}{|c|}{ Non-supine AHI, /h } \\
\hline Women & $13.1 \pm 15.3$ & $4.0 \pm 4.7$ & $-8.9 \pm 15.7$ & 0.0075 & \multirow[t]{2}{*}{ NS } \\
\hline Men & $19.6 \pm 17.9$ & $7.1 \pm 12.2$ & $-12.5 \pm 14.9$ & $<0.0001$ & \\
\hline \multicolumn{6}{|c|}{ Mean $\mathrm{SpO}_{2}, \%$} \\
\hline Women & $93.8 \pm 1.9$ & $94.0 \pm 1.9$ & $0.1 \pm 1.5$ & NS & \multirow[t]{2}{*}{ NS } \\
\hline Men & $93.7 \pm 1.9$ & $93.9 \pm 1.92$ & $0.2 \pm 1.8$ & NS & \\
\hline \multicolumn{6}{|c|}{ Nadir $\mathrm{SpO}_{2}, \%$} \\
\hline Women & $83.0 \pm 6.8$ & $85.3 \pm 8.9$ & $2.3 \pm 9.0$ & $<0.0001$ & \multirow[t]{2}{*}{ NS } \\
\hline Men & $81.3 \pm 8.0$ & $84.6 \pm 8.9$ & $3.3 \pm 9.9$ & $<0.0001$ & \\
\hline \multicolumn{6}{|c|}{$\mathrm{SpO}_{2}<90 \%, \min$} \\
\hline Women & $21.0 \pm 32.1$ & $10.7 \pm 22.8$ & $-7.3 \pm 29.2$ & 0.0018 & \multirow[t]{2}{*}{ NS } \\
\hline Men & $26.5 \pm 55.7$ & $18.0 \pm 52.7$ & $-9.1 \pm 57.3$ & $<0.0001$ & \\
\hline \multicolumn{6}{|l|}{ ODI, $/ \mathrm{h}$} \\
\hline Women & $21.8 \pm 19.3$ & $6.7 \pm 6.1$ & $-14.1 \pm 16.1$ & $<0.0001$ & \multirow[t]{2}{*}{ NS } \\
\hline Men & $21.7 \pm 18.1$ & $10.3 \pm 12.9$ & $-11.7 \pm 18.7$ & $<0.0001$ & \\
\hline \multicolumn{6}{|c|}{ Time in supine position, min } \\
\hline Women & $230 \pm 108$ & $221 \pm 132$ & $-51 \pm 99$ & 0.016 & \multirow[t]{2}{*}{0.0053} \\
\hline Men & $187 \pm 108$ & $205 \pm 110$ & $18 \pm 118$ & 0.07 & \\
\hline \multicolumn{6}{|c|}{ Time in non-supine position, min } \\
\hline Women & $194 \pm 135$ & $201 \pm 123$ & $35 \pm 92$ & NS & \multirow[t]{2}{*}{0.027} \\
\hline Men & $236 \pm 115$ & $217 \pm 114$ & $-25 \pm 124$ & 0.07 & \\
\hline
\end{tabular}

Values are mean \pm standard deviation

$A H I$ apnea-hypopnea index, $A I$ apnea index, $H I$ hypopnea index, $N S$ not significant, $O D I$ oxygen desaturation index, $\mathrm{SpO} 2$ oxygen saturation women. During MRD treatment, AI decreased significantly in men and women, but women continued to have a significantly lower AI. In patients with severe OSA, HI decreased to a significantly greater extent in women vs. men. The lower AI at baseline in women is consistent with data showing that middle-aged women have fewer apneic events compared with men of same age and BMI [22, 23]. A lower AI and larger decrease in $\mathrm{HI}$ contributed to the greater reduction in total respiratory events in women during MRD therapy. We have previously shown that both AI and HI were significant predictors of MRD treatment success in this population [11]. However, when analyzing men and women separately, decreases in AI and AHI were only independent predictors of treatment success and complete response in men. This could indicate that, in contrast to men, MRD efficacy in women is independent of OSA severity at baseline.

In this study, positional OSA did not appear to be associated with MRD success in women because supine and nonsupine AHI were similar at baseline and decreased significantly with no significant differences between women and men. Effects of MRD treatment on positional OSA are controversial. Several studies have suggested that supine OSA was a predictor of MRD efficacy [24, 25]. Others have reported that supine-dependent OSA predicted MRD treatment success after controlling for other factors, whatever the gender [26] or only in men [14], suggesting that positional OSA is less of an 
Table 3 Change in respiratory parameters during MRD therapy by patient sex and sleep apnea severity

\begin{tabular}{|c|c|c|c|c|c|c|c|}
\hline & \multirow[t]{2}{*}{ Number } & \multirow[t]{2}{*}{ Baseline } & \multirow[t]{2}{*}{ Number } & \multirow[t]{2}{*}{ Follow-up } & \multirow[t]{2}{*}{ Difference } & \multicolumn{2}{|l|}{$p$ value } \\
\hline & & & & & & Vs. baseline & Men vs. women \\
\hline \multicolumn{8}{|l|}{ AHI, /h } \\
\hline Women, mild-to-moderate OSA & 51 & $18.9 \pm 7.3$ & 48 & $6.5 \pm 5.4$ & $-19.3 \pm 11.7$ & $<0.0001$ & \multirow[t]{2}{*}{ NS } \\
\hline Men, mild-to-moderate OSA & 129 & $19.4 \pm 6.3$ & 114 & $11.6 \pm 13.20$ & $-18.7 \pm 12.6$ & $<0.0001$ & \\
\hline Women, severe OSA & 26 & $41.4 \pm 10.5$ & 22 & $8.7 \pm 6.37$ & $-32.2 \pm 8.2$ & $<0.0001$ & \multirow[t]{2}{*}{0.011} \\
\hline Men, severe OSA & 106 & $43.2 \pm 12.1$ & 96 & $18.3 \pm 16.25$ & $-25.0 \pm 14.8$ & $<0.0001$ & \\
\hline \multicolumn{8}{|l|}{$\mathrm{AI}, / \mathrm{h}$} \\
\hline Women, mild-to-moderate OSA & 50 & $6.2 \pm 6.1$ & 47 & $1.3 \pm 2.6$ & $-4.6 \pm 5.8$ & $<0.0001$ & \multirow[t]{2}{*}{ NS } \\
\hline Men, mild-to-moderate OSA & 129 & $7.1 \pm 5.8$ & 114 & $1.6 \pm 2.9$ & $-5.5 \pm 5.2$ & $<0.0001$ & \\
\hline Women, severe OSA & 26 & $15.1 \pm 10.7$ & 22 & $1.8 \pm 1.5$ & $-13.4 \pm 10.0$ & $<0.0001$ & \multirow[t]{2}{*}{ NS } \\
\hline Men, severe OSA & 106 & $21.8 \pm 14.6$ & 96 & $7.9 \pm 12.5$ & $-14.7 \pm 13.2$ & $<0.0001$ & \\
\hline \multicolumn{8}{|l|}{$\mathrm{HI}, / \mathrm{h}$} \\
\hline Women, mild-to-moderate OSA & 50 & $12.9 \pm 6.7$ & 47 & $4.2 \pm 3.3$ & $-8.7 \pm 6.4$ & $<0.0001$ & \multirow[t]{2}{*}{ NS } \\
\hline Men, mild-to-moderate OSA & 129 & $12.3 \pm 6.9$ & 114 & $4.5 \pm 4.2$ & $-7.9 \pm 7.6$ & $<0.0001$ & \\
\hline Women, severe OSA & 26 & $25.4 \pm 10.6$ & 22 & $6.9 \pm 5.7$ & $-17.2 \pm 10.1$ & $<0.0001$ & \multirow[t]{2}{*}{0.026} \\
\hline Men, severe OSA & 106 & $21.3 \pm 10.4$ & 96 & $10.4 \pm 9.5$ & $-10.4 \pm 12.9$ & $<0.0001$ & \\
\hline \multicolumn{8}{|l|}{ Supine AHI, /h } \\
\hline Women, mild-to-moderate OSA & 37 & $24.7 \pm 11.9$ & 42 & $6.8 \pm 5.5$ & $-18.0 \pm 12.4$ & $<0.0001$ & \multirow[t]{2}{*}{ NS } \\
\hline Men, mild-to-moderate OSA & 98 & $29.7 \pm 19.2$ & 93 & $7.5 \pm 7.8$ & $-21.7 \pm 18.1$ & $<0.0001$ & \\
\hline Women, severe OSA & 19 & $46.9 \pm 18.7$ & 17 & $9.3 \pm 9.3$ & $-33.8 \pm 17.6$ & $<0.0001$ & \multirow[t]{2}{*}{ NS } \\
\hline Men, severe OSA & 79 & $49.5 \pm 23.2$ & 77 & $21.4 \pm 22.9$ & $-27.2 \pm 27.2$ & $<0.0001$ & \\
\hline \multicolumn{8}{|l|}{ Non-supine AHI, /h } \\
\hline Women, mild-to-moderate OSA & 22 & $9.7 \pm 10.8$ & 22 & $3.3 \pm 4.8$ & $-6.3 \pm 10.0$ & 0.0008 & \multirow[t]{2}{*}{ NS } \\
\hline Men, mild-to-moderate OSA & 46 & $11.7 \pm 12.2$ & 51 & $3.4 \pm 4.5$ & $-8.3 \pm 13.2$ & $<0.0001$ & \\
\hline Women, severe OSA & 10 & $20.5 \pm 21.0$ & 9 & $5.6 \pm 4.1$ & $-17.7 \pm 25.6$ & NS & \multirow[t]{2}{*}{ NS } \\
\hline Men, severe OSA & 54 & $26.3 \pm 19.3$ & 43 & $11.5 \pm 16.4$ & $-16.2 \pm 15.5$ & $<0.0001$ & \\
\hline \multicolumn{8}{|l|}{ Time in supine position, min } \\
\hline Women, mild-to-moderate OSA & 25 & $220 \pm 96$ & 21 & $232 \pm 121$ & $-26 \pm 87$ & NS & \multirow[t]{2}{*}{0.033} \\
\hline Men, mild-to-moderate OSA & 53 & $159 \pm 99$ & 49 & $192 \pm 108$ & $26 \pm 126$ & 0.032 & \\
\hline Women, severe OSA & 11 & $254 \pm 133$ & 10 & $199 \pm 157$ & $-113 \pm 105$ & 0.016 & \multirow[t]{2}{*}{0.008} \\
\hline Men, severe OSA & 58 & $212 \pm 111$ & 46 & $219 \pm 111$ & $12 \pm 112$ & NS & \\
\hline \multicolumn{8}{|l|}{ Time in non-supine position, min } \\
\hline Women, mild-to-moderate OSA & 25 & $214 \pm 143$ & 21 & $213 \pm 121$ & $22 \pm 86$ & NS & \multirow[t]{2}{*}{ NS } \\
\hline Men, mild-to-moderate OSA & 52 & $270 \pm 95$ & 49 & $229 \pm 114$ & $-27 \pm 130$ & NS & \\
\hline Women, severe OSA & 9 & $137 \pm 92$ & 9 & $173 \pm 128$ & $78 \pm 105$ & NS & \multirow[t]{2}{*}{0.061} \\
\hline Men, severe OSA & 57 & $205 \pm 124$ & 46 & $204 \pm 114$ & $-23 \pm 120$ & NS & \\
\hline
\end{tabular}

Values are mean \pm standard deviation

AHI apnea-hypopnea index, $A I$ apnea index, $H I$ hypopnea index, Mild-to-moderate AHI 5-30/h, NS not statistically significant, Severe AHI > 30/h

issue for women. In contrast, MRD efficacy was not affected by supine-dependent OSA in some studies [17, 27]. These conflicting results may be explained by the ability of different MRD devices to stabilize the lower jaw in a forward position during supine position sleep [28]. Most, but not all, positiondependent OSA patients appear to maintain positional dependency during MRD therapy, so MRDs might provide additional therapeutic effect in terms of sleep position [29]. This was the case in our population, with time spent in the dorsal position decreasing significantly during MRD treatment in women with severe OSA, and time in the non-dorsal position was significantly longer in women. In contrast, time in the dorsal position increased significantly in men. Less time spent in the dorsal position in women may also contribute to the greater AHI reduction and greater decrease in arousals for severe OSA women during MRD therapy in our analysis. It is well known that the dorsal position promotes respiratory events and lateral position is considered to be protective against apnea [30].

OSA has a well-known deleterious impact on quality of life and functional status. When OSA severity and obesity are similar, women report lower health status than men [31]. In this study, quality of life improved significantly, and to a similar extent, in men and women. Improvements in quality of life 
Table 4 Univariate analysis of factors predicting therapy success and complete response $(\mathrm{AHI}<$ $10 / \mathrm{h})$ in men and women

\begin{tabular}{|c|c|c|}
\hline Variable & OR $(95 \% \mathrm{CI})$ & $p$ value \\
\hline \multicolumn{3}{|l|}{ Treatment success, men } \\
\hline Neck circumference $(\mathrm{cm})$ & $0.88(0.78 ; 0.99)$ & 0.033 \\
\hline Waist circumference $(\mathrm{cm})$ & $0.95(0.92 ; 0.98)$ & 0.001 \\
\hline Obesity & $0.30(0.12 ; 0.75)$ & 0.01 \\
\hline Dental class (class II vs. I) & $3.45(1.16 ; 10.25)$ & 0.07 \\
\hline Dental class (class III vs. I) & $1.63(0.34 ; 7.88)$ & 0.07 \\
\hline Overbite (mm) & $1.51(1.19 ; 1.89)$ & 0.0005 \\
\hline Maximum mandibular advancement (mm) & $1.18(1.03 ; 1.37)$ & 0.02 \\
\hline Overjet (mm) & $1.32(1.06 ; 1.65)$ & 0.01 \\
\hline Initial AHI (/h) & $0.97(0.95 ; 0.98)$ & 0.0013 \\
\hline Initial AI (/h) & $0.95(0.93 ; 0.98)$ & $<0.0001$ \\
\hline Initial supine AHI (/h) & $0.98(0.97 ; 0.99)$ & 0.02 \\
\hline Mouth breathing (yes/no) & $2.14(0.96 ; 4.74)$ & 0.06 \\
\hline \multicolumn{3}{|l|}{ Complete response, men } \\
\hline Neck circumference $(\mathrm{cm})$ & $0.81(0.72 ; 0.91)$ & 0.0003 \\
\hline Waist circumference $(\mathrm{cm})$ & $0.94(0.92 ; 0.97)$ & 0.0002 \\
\hline Neck circumference/waist circumference ratio & $\infty(0.91 ; \infty)$ & 0.05 \\
\hline Obesity & $0.24(0.10 ; 0.58)$ & 0.037 \\
\hline Dental class (class II vs. I) & $2.45(1.09 ; 5.51)$ & 0.07 \\
\hline Dental class (class III vs. I) & $1.84(0.47 ; 7.22)$ & 0.07 \\
\hline Overbite (mm) & $1.39(1.15 ; 1.67)$ & 0.0007 \\
\hline Overjet (mm) & $1.19(0.99 ; 1.43)$ & 0.06 \\
\hline Initial AHI (/h) & $0.91(0.89 ; 0.94)$ & $<0.0001$ \\
\hline Initial AI (/h) & $0.91(0.89 ; 0.94)$ & $<0.0001$ \\
\hline Initial HI (/h) & $0.96(0.93 ; 0.99)$ & 0.006 \\
\hline Initial supine AHI (/h) & $0.96(0.94 ; 0.98)$ & $<0.0001$ \\
\hline No previous treatment by CPAP (yes/no) & $3.24(1.77 ; 5.95)$ & 0.0001 \\
\hline Mouth breathing (yes/no) & $1.77(0.91 ; 3.44)$ & 0.094 \\
\hline \multicolumn{3}{|l|}{ Treatment success, women } \\
\hline Vertical dimension (mm) & $1.18(1.00 ; 1.39)$ & 0.05 \\
\hline Maximum mandibular advancement (mm) & $1.73(1.08 ; 2.78)$ & 0.02 \\
\hline Mandibular advancement (\%) & $0.97(0.94 ; 0.99)$ & 0.03 \\
\hline Initial AHI (/h) & $1.10(1.01 ; 1.21)$ & 0.03 \\
\hline Initial HI (/h) & $1.11(0.99 ; 1.24)$ & 0.07 \\
\hline Initial supine $\mathrm{AHI}(/ \mathrm{h})$ & $1.07(0.99 ; 1.16)$ & 0.08 \\
\hline \multicolumn{3}{|l|}{ Complete response, women } \\
\hline Neck circumference $(\mathrm{cm})$ & $0.83(0.68 ; 1.03)$ & 0.089 \\
\hline Mandibular advancement (\%) & $0.98(0.96 ; 1.0)$ & 0.09 \\
\hline Initial AHI (/h) & $0.94(0.89 ; 0.99)$ & 0.01 \\
\hline Initial AI (/h) & $0.94(0.88 ; 1.0)$ & 0.05 \\
\hline Initial HI (/h) & $1.11(0.99 ; 1.24)$ & 0.07 \\
\hline No previous CPAP treatment (yes/no) & $7.64(1.87 ; 31.33)$ & 0.005 \\
\hline
\end{tabular}

$A H I$ apnea-hypopnea index, $A I$ apnea index, $H I$ hypopnea index in women during MRD therapy are similar to those reported with CPAP [32]. Daytime sleepiness and fatigue were also similarly improved in men and women during MRD therapy, irrespective of OSA severity, and sleep structure was maintained.
Baseline OSA symptom severity was similar in men and women, as has been reported previously [33]. In contrast, sex differences in OSA symptoms and severity have also been documented. Women report typical OSA symptoms (e.g., snoring) less often than men and are more likely to report 
Table 5 Factors predicting short-term MRD efficacy on multivariate analysis

Odds $95 \% \mathrm{CI} \quad p$ value
ratio

\begin{tabular}{lccc}
\hline Whole population & & & \\
Success & & & \\
$\quad$ Overbite & 1.43 & $1.09-1.87$ & 0.0096 \\
$\quad$ Baseline apnea index & 0.96 & $0.94-0.98$ & 0.025 \\
Men & & & \\
Success & & & \\
$\quad \begin{array}{l}\text { Overbite } \\
\text { Baseline apnea index }\end{array}$ & 1.48 & $1.16-1.88$ & 0.0015 \\
Complete response & 0.95 & $0.93-0.98$ & 0.0002 \\
$\quad$ Baseline AHI & & & \\
$\begin{array}{l}\text { Women } \\
\text { Success } \\
\quad \text { Maximum mandibular } \\
\quad \text { advancement }\end{array}$ & 0.91 & $0.88-0.93$ & $<0.0001$ \\
Complete response & & & \\
$\quad \begin{array}{l}\text { Neck circumference } \\
\quad \text { No previous CPAP therapy }\end{array}$ & 1.72 & $1.07-2.77$ & 0.0236 \\
\hline
\end{tabular}

$A H I$ apnea-hypopnea index, $C I$ confidence interval, Complete response AHI $<10 / \mathrm{h}$, CPAP continuous positive airway pressure, Success $\geq 50 \%$ decrease in the AHI

general symptoms (e.g., fatigue, headache) [19, 34]. In our study, MRD therapy significantly reduced key OSA symptoms in men and women, and reduced morning headache to a greater extent in women than in men. Although women had a higher rate of hypothyroidism at baseline, all were receiving treatment for this condition and the rate was similar to that reported in the general population [34].

Mandibular advancement is associated with enlargement of the velo-pharynx and increased mandibular protrusion produces greater reductions in the AHI. We found no differences between men and women in the number of titration visits, degree of protrusion, and final mandibular advancement, but ability to protrude the mandible was an independent predictor of MRD treatment success in women only. However, it is interesting to note that a high percentage of women $(42.9 \%)$ vs. men $(21.2 \%)$ had type 2 angle malocclusion, irrespective of OSA severity. Greater overbite has been described as a significant predictor of treatment success, predisposing patients with class II division 2 malocclusions to a higher success rate [35]. This could have contributed to the higher treatment success rate in women in our study. Women with no previous CPAP therapy, experiencing MRD as first treatment, had higher therapy success rates, suggesting that MRD may be the best treatment for women, even in severe OSA.

Side effects were relatively common, but most were not severe. In our study, women who experienced side effects
Table 6 Side effects

\begin{tabular}{lccl}
\hline $\begin{array}{l}\text { \% Patients } \\
\text { Events }\end{array}$ & Women & Men & $p$ value \\
\hline Tooth pain & 18 & 15 & $\mathrm{NS}$ \\
Temporomandibular joint pain & 25 & 20 & $\mathrm{NS}$ \\
Occlusion change & 19 & 15 & $\mathrm{NS}$ \\
Gum irritation & 21 & 10 & 0.016 \\
Hypersalivation or mouth dryness & 6 & 9 & $\mathrm{NS}$ \\
Dental mobility or migration & 12 & 5 & 0.045 \\
MRD discontinuation & 12 & 7 & 0.017 \\
Severe side effects & 15 & 13 & $\mathrm{NS}$ \\
\hline
\end{tabular}

$M R D$ mandibular repositioning device, $N S$ not statistically significant

were more likely to discontinue therapy than men. Careful dental examination before MRD therapy is recommended, especially in women, to improve tolerability and maximize treatment adherence.

This study had some limitations. The design was observational, and there was an imbalance in the number of men and women, consistent with existing OSA prevalence data. Menopausal status of women was not documented, but the number of women aged $>60$ years (when most women are post-menopausal) was low. PSG was performed in only 149 subjects and OSA severity by sleep stage was not documented so we could not determine whether these differed between women and men, as described previously [9]. Study strengths include the lack of existing data in this area, and the inclusion and follow-up of patients by a multidisciplinary sleep and dental team. In addition, only CAD/CAM MRD devices were used and these were custom-made for each patient.

In conclusion, our results show that $\mathrm{CAD} / \mathrm{CAM}$ MRD is an effective treatment option in women with OSA of any severity, particularly those with severe OSA, due to some specific OSA phenotypes in women. Predictors of treatment success varied between men and women. These gender-specific differences in the response to MRD treatment need to be taken into account when deciding on the most appropriate therapeutic strategy for an individual OSA patient.

Acknowledgements Editing assistance was provided by Nicola Ryan, independent medical writer, funded by ResMed.

ORCADES Investigators listing: Dr Darius Abedipour, Cabinet médical, Lyon, France; Dr Aurélie Allard-Redon, Cabinet dentaire, Behren les Forbach, France; Dr Alexandre Aranda, Clinique de l'Union, Service de Neurologie, Saint Jean, France; Dr Valérie Attali, Hôpital Pitié Salpêtrière Service du Sommeil, Paris, France; Dr Frédérique Bavozet, $\mathrm{CH}$ de Valence, Service ORL, Valence, France; Dr Martine Becu, CHG de Chalons en Champagne, Service de Pneumologie, Chalons en Champagne, France; Dr Wally Beruben, Cabinet Dentaire, Chalons en Champagne, France; Dr Jerome Bessard, 
Clinique de l'Union, Service d'Odontologie, Saint Jean, France; Dr Isabelle Bonafe, Faculté d'odontologie, Montpellier, France; Dr Mohammed Boukhana, Centre du sommeil, Metz, France; Dr Bruno Chabro, Cabinet Dentaire, Creil, France; Dr Gérard Chatte, Cabinet médical, Caluire, France; Dr Chauvel Lebret, CHU Rennes, Pôle d'Odontologie et Chirurgie Buccale, Rennes, France; Dr Jean-Marc Collet, Hôpital Pitié Salpêtrière Service de Stomatologie et Chirurgie Maxillo-Faciale, Paris, France; Dr Olivier Coste, Polyclinique du Tondu, Bordeaux, France; Dr Nathalie Dumont, Cabinet medical, Marseille, France; Dr Sophie Durand-Amat, Cabinet médical, Lagny sur Marne, France; Pr Marie-Pia D'ortho, Groupe Hospitalier Bichat Service de Physiologie-Explorations fonctionnelles, Paris, France; Dr Jean Marc Elbaum, Cabinet Medical, Marseille, France; Dr olivier Gallet de Santerre, Clinique Beau Soleil, Montpellier, France; Dr Frédéric Goutorbes, Centre Hospitalier de Beziers, Service de Pneumologie, Beziers, France; Dr Thierry Grandjean, Cabinet dentaire, Schœneck, France; Dr Wilma Guyot, Cabinet Dentaire, Vandoeuvre les Nancy, France; Dr Doniphan Hammer, Espace Médical Rabelais, Poitiers, France; Dr Carmen Havasi, Cabinet Dentaire, Nice, France; Dr Pascal Huet, Clinique Bretéché, Nantes, France; Dr Jean Baptiste Kerbrat, CHRU de Rouen-Hopital Charles Nicolle, Service de Maxillo-Faciale, Rouen, France; Dr Hauria Khemliche, Centre Hospitalier de Senlis Avenue Paul Rougé Unité Sommeil, Senlis, France; Dr Christian Koltes, Centre du sommeil, Metz, France; Pr Damien Leger, Hôtel Dieu de Paris Centre de Sommeil, Paris, France; Dr Laurent Lacassagne, Clinique de l'Union, Service de Pneumologie, Saint Jean, France; Dr Xavier Laur, Cabinet Dentaire, Castres, France; Dr Lionel Lerousseau, Centre Hospitalier d'Antibes, Service de Pneumologie, Antibes, France; Dr Olivier Liard, Cabinet Dentaire, Albi, France; Dr Christophe Loisel, Cabinet dentaire Lagny sur Marne, France; Dr Matthieu Longuet, Centre Hospitalier de Beziers, Service ORL, Beziers, France; Dr Anne Mallart, Hôpital Roger Salengro Service de Neurologie Clinique, Lille, France; Dr Francis Martin, Centre Hospitalier de CompiègneService de Pneumologie, Unité des pathologies du Sommeil, Compiègne, France; Dr Frédéric Merle Beral, Clinique de l'Union, Service d'Odontologie, Saint Jean, France; Pr Jean Claude Meurice, CHU de Poitiers, Service de Pneumologie, Poitiers, France; Dr Zoubida Mokhtari, Centre Hospitalier de Senlis Avenue Paul Rougé Unité Sommeil, Senlis, France; Dr Christelle Monaca, Hôpital Roger Salengro Service de Neurologie Clinique, Lille, France; Dr Pierre Jean Monteyrol, Polyclinique du Tondu, Bordeaux, France; Pr Jean-François Muir, CHU de Rouen- Hôpital de Bois Guillaume Service de Pneumologie, Rouen, France; Dr Eric Mullens, Fondation Bon Sauveur, Laboratoire de Sommeil, Albi, France; Dr Dominique Muller, Cabinet médical, Metz, France; Dr Charles Paoli, CH Montreuil, Montreuil, France; Dr François Xavier Petit, Maison de la Mutualité, Nantes, France; Dr Bernard Pigearias, Cabinet de Pneumologie, Laboratoire du Sommeil et de l'Effort, Nice, France; Dr Marc Pradines, Cabinet Dentaire, Toulouse, France; Dr Arnauld Prigent, Clinique St Laurent, Service de Pneumologie, Rennes, France; Dr Gil Putterman, Hôtel Dieu de Paris, Service de Stomatologie Paris, France; Dr Marc Rey, CHU Timone, Centre du Sommeil de Neurophysiologie, Marseille, France; Dr Mickael Samama, Hôpital Pitié Salpêtrière Service de Stomatologie et Chirurgie Maxillo-Faciale, Paris, France; Pr Renaud Tamisier, CHU de Grenoble, Physiologie, sommeil et exercice, Grenoble, France; Dr Michel Tiberge, CHU de Rangueil, Service de Neurologie et Explorations Fonctionnelles Neurologiques, Toulouse, France; Dr Cyrille Tison, Hôpital Roger Salengro, Service de Stomatologie, Lille, France; Dr Fabienne Tordjman, Hôpital Pitié Salpêtrière Service du Sommeil, Paris, France; Dr Bernard Triolet, Cabinet Dentaire Ribecourt Dreslincourt, France; Pr Christian Vacher, Hôpital Beaujon Service de Chirurgie Maxillo-Faciale et Stomatologie, Clichy, France; Dr Marie-Françoise Vecchierini, Hôtel Dieu Centre de Sommeil, Paris, France; Dr Alain Verain, CHU de Grenoble, service odontologie, Grenoble, France

\section{Compliance with ethical standards}

Funding The ORCADES study and the preparation of this article were funded by ResMed (France).

Conflict of interest Marie-Francoise Vecchierini has received fees for serving on advisory boards and lecture fees from ResMed and Fisher \& Paykel Healthcare. Valérie Attali has received fees for serving on advisory boards from Somnomed, and lecture fees and unrestricted grant support from ResMed. Marie-Pia d'Ortho has received fees for serving on advisory boards from ResMed and IP Santé; lecture fees from ResMed, Philips, IP Santé, and VitalAire; grant support from Fisher and Paykel Healthcare, ResMed, Philips, ADEP-Assistance, and IP Santé; and small material donations from VitalAire. Damien Léger has been a primary investigator for studies sponsored by Vitalair and Philips over the last 5 years and declares no other conflicts of interest regarding this publication. Florent Lavergne is an employee of ResMed. Christelle Monaca has received fees for serving on advisory boards from ResMed, Philips and UCB Pharma, and lecture fees from UCB Pharma and Orkyn. Laurent Morin is an employee of ResMed. Francis Martin has received lecture fees from ResMed, Philips, ADEP-ASSISTANCE; grant support from ResMed, Philips, ADEP Assistance, Orkyn and FranceOxygène; and small material donations from ADEP-ASSISTANCE. JeanClaude Meurice has received fees for serving on advisory boards, lectures, and training sessions from ResMed, Philips, Orkin, and Novartis. For the remaining authors, none were declared.

Ethical approval The trial received ethics committee approval on December 17, 2010. All procedures performed in this study were in accordance with the international and national ethical standards and with the 1964 Helsinki declaration and its later amendments or comparable ethical standards.

Informed consent All patients gave written informed consent to participate in the study.

Open Access This article is distributed under the terms of the Creative Commons Attribution 4.0 International License (http:// creativecommons.org/licenses/by/4.0/), which permits unrestricted use, distribution, and reproduction in any medium, provided you give appropriate credit to the original author(s) and the source, provide a link to the Creative Commons license, and indicate if changes were made.

Publisher's note Springer Nature remains neutral with regard to jurisdictional claims in published maps and institutional affiliations.

\section{References}

1. Heinzer R, Vat S, Marques-Vidal P, Marti-Soler H, Andries D, Tobback N, Mooser V, Preisig M, Malhotra A, Waeber G, Vollenweider P, Tafti M, Haba-Rubio J (2015) Prevalence of sleep-disordered breathing in the general population: the HypnoLaus study. Lancet Respir Med 3(4): 310-318. https://doi.org/10.1016/s2213-2600(15)00043-0

2. Liu T, Li W, Zhou H, Wang Z (2017) Verifying the relative efficacy between continuous positive airway pressure therapy and its alternatives for obstructive sleep apnea: a network meta-analysis. Front Neurol 8:289. https://doi.org/10.3389/fneur.2017.00289

3. Tregear S, Reston J, Schoelles K, Phillips B (2010) Continuous positive airway pressure reduces risk of motor vehicle crash among drivers with obstructive sleep apnea: systematic review and metaanalysis. Sleep 33(10):1373-1380

4. Khan SU, Duran CA, Rahman H, Lekkala M, Saleem MA, Kaluski E (2017) A meta-analysis of continuous positive airway pressure therapy in prevention of cardiovascular events in patients with 
obstructive sleep apnoea. Eur Heart J 39:2291-2297. https:/doi. org/10.1093/eurheartj/ehx597

5. Sawyer AM, Gooneratne NS, Marcus CL, Ofer D, Richards KC, Weaver TE (2011) A systematic review of CPAP adherence across age groups: clinical and empiric insights for developing CPAP adherence interventions. Sleep Med Rev 15(6):343-356. https://doi. org/10.1016/j.smrv.2011.01.003

6. Weaver TE, Grunstein RR (2008) Adherence to continuous positive airway pressure therapy: the challenge to effective treatment. Proc Am Thorac Soc 5(2):173-178. https://doi.org/10.1513/pats.200708-119MG

7. Sutherland K, Vanderveken OM, Tsuda H, Marklund M, Gagnadoux F, Kushida CA, Cistulli PA (2014) Oral appliance treatment for obstructive sleep apnea: an update. J Clin Sleep Med 10(2):215-227. https://doi.org/10.5664/jcsm.3460

8. Almeida FR, Henrich N, Marra C, Lynd LD, Lowe AA, Tsuda H, Fleetham JA, Pliska B, Ayas N (2013) Patient preferences and experiences of CPAP and oral appliances for the treatment of obstructive sleep apnea: a qualitative analysis. Sleep Breath 17(2): 659-666. https://doi.org/10.1007/s11325-012-0739-6

9. Jordan AS, McEvoy RD (2003) Gender differences in sleep apnea: epidemiology, clinical presentation and pathogenic mechanisms. Sleep Med Rev 7(5):377-389

10. Jordan AS, Wellman A, Edwards JK, Schory K, Dover L, MacDonald M, Patel SR, Fogel RB, Malhotra A, White DP (2005) Respiratory control stability and upper airway collapsibility in men and women with obstructive sleep apnea. J Appl Physiol (1985) 99(5):20202027. https://doi.org/10.1152/japplphysiol.00410.2004

11. Vecchierini MF, Attali V, Collet JM, d'Ortho MP, El Chater P, Kerbrat JB, Leger D, Monaca C, Monteyrol PJ, Morin L, Mullens E, Pigearias B, Meurice JC, investigators O (2016) A custom-made mandibular repositioning device for obstructive sleep apnoeahypopnoea syndrome: the ORCADES study. Sleep Med 19:131140. https://doi.org/10.1016/j.sleep.2015.05.020

12. Sleep-related breathing disorders in adults: recommendations for syndrome definition and measurement techniques in clinical research (1999) The Report of an American Academy of Sleep Medicine Task Force. Sleep 22(5):667-689

13. Cartwright RD (1984) Effect of sleep position on sleep apnea severity. Sleep 7(2):110-114

14. Marklund M, Stenlund H, Franklin KA (2004) Mandibular advancement devices in 630 men and women with obstructive sleep apnea and snoring: tolerability and predictors of treatment success. Chest 125(4):1270-1278

15. Sutherland K, Takaya H, Qian J, Petocz P, Ng AT, Cistulli PA (2015) Oral appliance treatment response and polysomnographic phenotypes of obstructive sleep apnea. J Clin Sleep Med 11(8): 861-868. https://doi.org/10.5664/jcsm.4934

16. Simpson L, Mukherjee S, Cooper MN, Ward KL, Lee JD, Fedson AC, Potter J, Hillman DR, Eastwood P, Palmer LJ, Kirkness J (2010) Sex differences in the association of regional fat distribution with the severity of obstructive sleep apnea. Sleep 33(4):467-474

17. Ferguson KA, Cartwright R, Rogers R, Schmidt-Nowara W (2006) Oral appliances for snoring and obstructive sleep apnea: a review. Sleep 29(2):244-262

18. Mehta A, Qian J, Petocz P, Darendeliler MA, Cistulli PA (2001) A randomized, controlled study of a mandibular advancement splint for obstructive sleep apnea. Am J Respir Crit Care Med 163(6): 1457-1461. https://doi.org/10.1164/ajrccm.163.6.2004213

19. Lin CM, Davidson TM, Ancoli-Israel S (2008) Gender differences in obstructive sleep apnea and treatment implications. Sleep Med Rev 12(6):481-496. https://doi.org/10.1016/j.smrv.2007.11.003

20. Malhotra A, Huang Y, Fogel RB, Pillar G, Edwards JK, Kikinis R, Loring SH, White DP (2002) The male predisposition to pharyngeal collapse: importance of airway length. Am J Respir Crit Care Med 166(10):1388-1395. https://doi.org/10.1164/rccm.2112072

21. Lee CH, Kim JW, Lee HJ, Seo BS, Yun PY, Kim DY, Yoon IY, Rhee CS, Park JW, Mo JH (2010) Determinants of treatment outcome after use of the mandibular advancement device in patients with obstructive sleep apnea. Arch Otolaryngol Head Neck Surg 136(7):677-681. https://doi.org/10.1001/archoto.2010.106

22. Quintana-Gallego E, Carmona-Bernal C, Capote F, SanchezArmengol A, Botebol-Benhamou G, Polo-Padillo J, CastilloGomez J (2004) Gender differences in obstructive sleep apnea syndrome: a clinical study of 1166 patients. Respir Med 98(10):984-989

23. Ware JC, McBrayer RH, Scott JA (2000) Influence of sex and age on duration and frequency of sleep apnea events. Sleep 23(2):165-170

24. Marklund M, Persson M, Franklin KA (1998) Treatment success with a mandibular advancement device is related to supinedependent sleep apnea. Chest 114(6):1630-1635

25. Yoshida K (2001) Influence of sleep posture on response to oral appliance therapy for sleep apnea syndrome. Sleep 24(5):538-544

26. Chung JW, Enciso R, Levendowski DJ, Morgan TD, Westbrook PR, Clark GT (2010) Treatment outcomes of mandibular advancement devices in positional and nonpositional OSA patients. Oral Surg Oral Med Oral Pathol Oral Radiol Endod 109(5):724-731. https://doi.org/10.1016/j.tripleo.2009.11.031

27. Dieltjens M, Braem MJ, Van de Heyning PH, Wouters K, Vanderveken OM (2014) Prevalence and clinical significance of supine-dependent obstructive sleep apnea in patients using oral appliance therapy. J Clin Sleep Med 10(9):959-964. https://doi. org $/ 10.5664 / j \mathrm{jsm} .4024$

28. Marklund M (2017) Update on oral appliance therapy for OSA. Curr Sleep Med Rep 3(3):143-151. https://doi.org/10.1007/ s40675-017-0080-5

29. Lee CH, Hong SL, Rhee CS, Kim SW, Kim JW (2012) Analysis of upper airway obstruction by sleep videofluoroscopy in obstructive sleep apnea: a large population-based study. Laryngoscope 122(1): 237-241. https://doi.org/10.1002/lary.22344

30. Zhu K, Bradley TD, Patel M, Alshaer H (2017) Influence of head position on obstructive sleep apnea severity. Sleep Breath 21(4): 821-828. https://doi.org/10.1007/s11325-017-1525-2

31. Theorell-Haglow J, Miller CB, Bartlett DJ, Yee BJ, Openshaw HD, Grunstein RR (2018) Gender differences in obstructive sleep apnoea, insomnia and restless legs syndrome in adults - what do we know? A clinical update Sleep Med Rev 38:28-38. https://doi.org/ 10.1016/j.smrv.2017.03.003

32. Campos-Rodriguez F, Queipo-Corona C, Carmona-Bernal C, Jurado-Gamez B, Cordero-Guevara J, Reyes-Nunez N, TroncosoAcevedo F, Abad-Fernandez A, Teran-Santos J, CaballeroRodriguez J, Martin-Romero M, Encabo-Motino A, Sacristan-Bou L, Navarro-Esteva J, Somoza-Gonzalez M, Masa JF, SanchezQuiroga MA, Jara-Chinarro B, Orosa-Bertol B, Martinez-Garcia MA, Spanish Sleep N (2016) Continuous positive airway pressure improves quality of life in women with obstructive sleep apnea. A randomized controlled trial. Am J Respir Crit Care Med 194(10): 1286-1294. https://doi.org/10.1164/rccm.201602-0265OC

33. Young T, Hutton R, Finn L, Badr S, Palta M (1996) The gender bias in sleep apnea diagnosis. Are women missed because they have different symptoms? Arch Intern Med 156(21):2445-2451

34. Ye L, Pien GW, Weaver TE (2009) Gender differences in the clinical manifestation of obstructive sleep apnea. Sleep Med 10(10): 1075-1084. https://doi.org/10.1016/j.sleep.2009.02.006

35. Milano F, Billi MC, Marra F, Sorrenti G, Gracco A, Bonetti GA (2013) Factors associated with the efficacy of mandibular advancing device treatment in adult OSA patients. Int Orthod 11(3):278289. https://doi.org/10.1016/j.ortho.2013.05.006 